\title{
Periódicos científicos na America Latina: títulos em acesso aberto indexados no ISI e SCOPUS
}

Rosângela Schwarz Rodrigues

\begin{abstract}
Professora do Programa de Pós-Graduação em Ciência da Informação da Universidade Federal de Santa Catarina (UFSC)
\end{abstract}

\section{Aline Borges de Oliveira}

\author{
Bolsista de Iniciação Científica 2011-2012 no \\ curso de Biblioteconomia da Universidade Federal \\ de Santa Catarina (UFSC)
}

Esta pesquisa tem como objetivo analisar o acesso aos periódicos dos países latino-americanos. Os objetivos específicos são: a) identificar as revistas indexadas no ISI-Thompson Reuters e na Sciverse Scopus em acesso aberto; b) descrever os aspetos institucionais das revistas; e c) identificar as características técnicas. A abordagem da metodologia é exploratória, com análise documental e estatística descritiva. Os dados foram coletados por meio de formulário e com informações obtidas nas páginas das revistas e no Ulrich. O universo da pesquisa é composto por 556 títulos indexados em pelo menos uma das bases e distribuídos por 11 países. Os resultados mostram que $98 \%$ dos periódicos estão em acesso aberto, a maioria no Brasil, 45\% (241), seguido do Chile e México, ambos com 13,6\% cada. As universidades são as entidades editoras responsáveis pela maioria dos títulos (45\%), seguidas das Associaçoes, com 34,7\%, a maioria da área médica. $O$ uso da plataforma Scielo explica, em parte, a dominância do Acesso Aberto, pois $69 \%$ (370) do total de títulos usam os recursos dessa biblioteca. A conclusão indica uma quantidade muito acima de outras regiões de periódicos qualificados em acesso aberto. Isso acontece devido à associação de dois elementos principais: a ação dos grupos das universidades e associações e o uso intensivo da plataforma Scielo.

Palavras-chave: Acesso aberto; Periódicos científicos; Comunicação científica. 


\section{Scientific Periodicals in Latin America: open access titles indexed by Thompson Reuters ISI and Sciverse Scopus}

This research analyze scientific journals from Latin American countries.The specific goals are: a) identify Open Access magazines indexed by ISI-Thompson Reuters and Sciverse Scopus; b) describe the institutional aspects of these journals; and c) identify its technical features. The methodological approach used is exploratory, with documental analysis and descriptive statistics. The data was collected through forms with information from the journals magazines and Ulrich. This research is based on 556 titles, from 11 countries, indexed by at least one of the databases. The results show that $98 \%$ of the journals are open access and most of them are from Brazil (45\%), followed by Chile and Mexico, with $13.6 \%$ each. Universities are responsible for $45 \%$ of the titles, followed by Associations, with $34.7 \%$, most of them in Medicine. Scielo Platform is used by $69 \%$ (370) of the titles. The conclusion is the very high incidence of quality journals in Open Access in Latin America is due to two main factors associated: the work of scientific comunities from universities and associations and the wide use of Scielo.

Keywords: Open access; Scientific journals; Scientific communication.

Recebido em 18.09.2012 Aceito em 10.12.2012

\section{Introdução}

Estudos sobre periódicos digitais têm aumentado na última década, seguindo a expansão do número de títulos. A importância crescente da Ciência e Tecnologia, como fator de desenvolvimento social e político, aumenta a demanda por estudos para refletir e compreender os elementos envolvidos no canal mais importante de informação e comunicação da ciência: o periódico científico.

A evolução tecnológica tem mudado os cenários para a divulgação científica, gerando um debate sobre a via Verde (depósito de artigos já publicados em periódicos, em repositórios temáticos ou institucionais) e a via Dourada (periódicos em acesso aberto), dando origem a novos 
modelos de publicação. O debate, aquecido pela paixão das discussões em muitos contextos e suas amplas consequências, demanda que estudos baseados em evidências sejam trazidos para a discussão (BROWN, 2010).

Enquanto em parte da Europa, nos EUA e no Canadá, o Acesso Aberto tem sido impulsionado pelo aumento nos preços dos periódicos e no aumento da quantidade de títulos nas diversas áreas, as motivações na América Latina têm sido diferentes e são a explicação para sua ampla adoção (ALPERIN; FISCHMAN; WILLINSKY, 2008). De acordo com TerraFigari (2008), o conceito de Acesso Aberto na América Latina tem uma abordagem própria, uma vez que a questão principal é atender à falta de periódicos e não apenas reagir ao custo elevado das publicações. Os países do sul da Europa têm características similares aos da América Latina: eles usam idiomas que não é o inglês, habitual da comunicação científica, não têm uma indústria editorial forte e investem uma menor porcentagem do PIB em pesquisas (ABADAL et al., 2010).

A situação dos periódicos acadêmicos em Acesso Aberto nos países latino-americanos é uma questão que carece de estudos, em função das rápidas e importantes mudanças no cenário editorial. Os indícios de que esteja se formando uma "rede de periódicos científicos", em Acesso Aberto, sob a liderança das universidades, nestes países (TERRA-FIGARI, 2008; GARRIDO, RODRIGUES, 2010), necessitam de detalhamento e análises quantitativas para refinamento e discussão.

O objetivo desta pesquisa é analisar a situação dos periódicos acadêmicos em Acesso Aberto nos países latino-americanos. Os objetivos específicos são: a) identificar as revistas indexadas no ISI-Thompson Reuters e na Sciverse Scopus em Acesso Aberto; b) descrever as características institucionais das revistas: a entidade editorial, a área do conhecimento, o idioma dos artigos, o ano de criação e a periodicidade; e c) apontar os recursos tecnológicos utilizados: a plataforma editorial, o uso de identificador persistente, o uso do Creative Commons e o tipo de arquivo. Esta estratégia busca identificar como está acontecendo o movimento de Acesso Aberto via Dourada dos periódicos de qualidade internacionalmente reconhecidos, por meio do estudo de suas principais características.

\section{Periódicos Científicos}

As revistas científicas se estabelecem como os principais meios de comunicação e divulgação dos avanços da Ciência, como espaços de diálogo para as comunidades das diversas áreas (GUÉDON, 2010; PATALANO, 2005). Ziman (1979, p. 63) explica que "a atividade científica é guiada por ideias, por teorias, pelo desejo de se obter informação significativa".

As revistas científicas começaram a ser publicadas no século XVII, na França e na Inglaterra, e surgiram da necessidade de obter uma comunicação rápida entre os cientistas (STUMPF, 1996; MEADOWS, 1999; BURKE, 2003). Freire (2006, p. 3) destaca que: 
A criação da tecnologia de impressão foi muito importante no desenvolvimento das forças produtivas na sociedade, ao facilitar a circulação da mesma informação com um alcance sem precedentes. Inicia-se, então, um processo de comunicação científica, na medida em que a produção de conhecimentos gera, por sua vez, a necessidade de novos conhecimentos. Isso merece ser destacado, uma vez que nesse período foram iniciadas as bases da nossa sociedade atual, que começou a ser construída quando as associações científicas foram criadas e os primeiros periódicos científicos são publicados, dando início à formalização do processo de comunicação científica.

A necessidade de registro de autoria, na Ciência, aumenta o reconhecimento e o empenho dos pesquisadores para publicar em revistas de prestígio, cuja visibilidade é maior do que nas publicações menos lidas e menos conceituadas. Desde seu início, os periódicos científicos desenvolveram modos de seleção dos artigos submetidos, com o expresso propósito de controlar a qualidade do que é publicado (MEADOWS, 1999, GUÉDON, 2001; ZIMAN, 1979; 1981).

O processo de revisão cega pelos pares é um dos critérios que assegura a confiabilidade das informações publicadas, proporcionando aos periódicos científicos o status de principal canal de comunicação formal da Ciência. Conforme explica Guédon (2001, p. 31), "as revistas científicas trabalham como um dispositivo de função tripla: a) uma ferramenta de atribuição de prestígio; b) a chave para o título de propriedade de determinado elemento que possa ser citado (resultados, figuras, parágrafos, etc); e c) instrumento de avaliação de desempenho individual de cientistas".

Em todas as áreas do conhecimento, os periódicos funcionam como filtro para reconhecer os trabalhos válidos e as taxas de rejeição funcionam como um dos indicadores de qualidade. A publicação em uma revista reconhecida pela área é a forma mais aceita para registrar a originalidade do trabalho e para confirmar que os resultados foram confiáveis o suficiente para superar o ceticismo da comunidade científica.

A revisão contínua e a necessidade de convencer os colegas especialistas da precisão, pertinência e confiabilidade dos resultados obtidos implica que os resultados da tarefa de pesquisa só são alcançados por meio de uma comunicação formal nos canais aceitos pela comunidade científica. Esse sistema conecta resultados da investigação de diferentes grupos preocupados com problemas comuns e, assim, garante o espaço para a discussão formal, que aceita o conflito sobre reputações e interpretações como parte do processo para a confiabilidade. As publicações científicas são a estrutura principal para o controle das normas e de processos de trabalhos de pesquisa, bem como o locus das negociações sobre a relevância de metas e prioridades acadêmicas (WHITLEY, 1984). 
A forma como a confiabilidade é assegurada, por meio dos sistemas de revisão cega de pares e pelas recomendações dos revisores, faz com que só os melhores trabalhos sejam publicados. Um artigo publicado em um periódico deve ser aprovado pelo editor, em primeira instância, e pelos avaliadores que $o$ analisaram e 0 aprovaram com ou sem recomendação de ajustes. Como o editor e os revisores representam os cientistas da área, fica explícito que consideraram o trabalho do autor bom o suficiente para ser publicado e aprovado para citações pela comunidade científica (MULLER, 2006; ZIMAN, 1979).

Com o surgimento da Word Wid Web e das TICs, na década de 1990, as possibilidades de acesso e de recuperação da informação começaram a mudar. Com o desenvolvimento das tecnologias, os periódicos começaram a migrar do impresso para o eletrônico num ritmo acelerado. O novo suporte digital possibilitou romper as barreiras de tempo e de distância, além de eliminar os custos de distribuição, transferindo para o leitor os custos de impressão (SANTOS JUNIOR, 2010; SILVA; SANTOS; PRAZERES, 2011).

Os periódicos científicos se destacam como principal meio de visibilidade científica, a disseminação dos artigos com o resultados das pesquisas é essencial para manter os pesquisadores a par dos novos trabalhos considerados válidos pelos especialistas da área. As tecnologias de informação mudaram a interface e os serviços possíveis, eliminando os limites geográficos em escala mundial de forma instantânea.

\subsection{Acesso aberto}

No final da década de 90, movimentos a favor do Acesso Aberto começaram a surgir. Foi criada a Iniciativa dos Arquivos Abertos (Open Archives Initiative - OAI), que defende o acesso livre, gratuito e irrestrito aos resultados de pesquisas científicas e/ou acadêmicas via WEB (KURAMOTO, 2006; SANTOS JUNIOR, 2010; SAYÃO, 2010).

O movimento a favor do Acesso Aberto se baseia no pressuposto de que todas as publicações financiadas com recursos públicos já estão pagas e devem estar disponíveis para todos, sem custo adicional. A meta principal dessa iniciativa é tornar a comunicação científica uma estrutura de publicação aberta, na qual toda a sociedade tenha acesso (KURAMOTO, 2006; SWAN, 2008; MUELLER, 2006; 2011). Segundo Abadal (2012), as revistas em acesso aberto giram em torno de $20 \%$ do total de títulos.

Os desdobramentos das iniciativas geraram novas necessidades para regulamentar o direito autoral das obras publicadas na internet. Em 2001, foi criada a iniciativa Creative Commons (CANESSA; ZENNARO, 2008). Lima e Santini (2008, p. 12) destacam que "A finalidade do Creative Commons é simplificar, para os criadores, o processo de expressar a sua concessão de uso".

Segundo Bailey Jr. (2006), as principais características das revistas em Acesso Aberto são: a) serem acadêmicas; b) utilizarem mecanismos de controle de qualidade, como os de revistas convencionais (por exemplo, a supervisão editorial e edição de texto); c) serem digitais; d) 
serem livremente disponíveis; e) permitirem que os autores mantenham seus direitos autorais; e f) utilizarem as licenças Creative Commons ou similar.

Os periódicos científicos de Acesso Aberto beneficiam a sociedade como um todo, eliminando as barreiras de preço dos periódicos aos leitores e tornando a comunicação entre os pesquisadores mais rápida.

\section{Metodologia}

O estudo desenvolvido está classificado como exploratório e descritivo, com análise documental predominantemente quantitativa (GIL, 2008; MOREIRA, 2005). Foi utilizado, como instrumento de coleta de dados, um formulário com 14 itens para cada título e usou-se estatística descritiva para discutir os resultados. Para atender ao objetivos: a identificar as revistas em acesso aberto - foram registrados o país, o título, o INSS e a fonte indexadora do periódico; b - descrever as características institucionais - foram coletados os dados de entidade editoria, área do conhecimento, idioma dos artigos, ano de criação e periodicidade; e c - apontar os recursos tecnológicos - foram registrados a plataforma editorial, a existência de identificador persistente, o uso do Creative Commons e o tipo de arquivo dos artigos.

Para a coleta dos dados, Bjork, Welling, Laakso, Majlender, Hedlund e Guõnason (2010) recomendam utilizar as listas de revistas fornecidas por índices como o Web of Science, SCOPUS Ulrichs, DOAJ, uma vez que nenhum abrange todos os periódicos. As listas contêm diferentes quantidades de periódicos, sendo a Ulrich a lista mais abrangente, com aproximadamente 92.000 títulos com revisão de pares; a Sciverse Scopus com 19.000; e a Thompson Reuters ISI Web of Science com 10.000 em todos os países (ABADAL, 2012). O ISI é considerado o índice mais importante e rigoroso em todas as áreas do conhecimento, seguido da Sciverse Scopus, que tem uma melhor cobertura das áreas de Humanidades e áreas Sociais, assim como de títulos que não usam o inglês como idioma.

O universo da pesquisa é formado pelos periódicos científicos de Acesso Aberto latino-americanos indexados no Thompson Reuters ISI e por periódicos indexados no Sciverse Scopus. Esta estratégia foi utilizada para garantir que apenas títulos com qualidade reconhecida internacionalmente pelos pares fossem considerados, assim a discussão sobre qualidade dos periódicos fica fora do escopo do trabalho. Entendese que existem títulos de qualidade que não fizeram parte da amostra e acredita-se na relevância das discussões sobre a representação de títulos das áreas de Humanas e Sociais nessas bases, que é uma das limitações do estudo. A coleta dos dados realizou-se de outubro de 2011 a março de 2012, consultando-se a página de cada revista e a base Ulrich, para sanar dúvidas ou lacunas. Utilizou-se o método de alfabetação para verificar quais títulos de periódicos latino-americanos estavam repetidos na lista do Thompson Reuters ISI e Sciverse Scopus (BARBETTA, 2004; SAMPIERI; COLLADO; LUCIO, 2006). 
Duas questões importantes surgiram durante os testes: na análise das áreas do conhecimento, a opção foi agrupar todos os títulos conforme as áreas do SCOPUS, tanto por ter o maior número de títulos e necessitar de menos adaptações quanto como pela maior abrangência. Os testes indicaram que $19 \%$ dos títulos estão cadastrados em mais de uma área. Nos resultados gerais, considerou-se apenas a primeira área de cada título, para manter-se a uniformidade da análise. A entidade editorial agrupou as associações profissionais e as associações científicas com a denominação genérica de associações, pois os testes indicaram a impossibilidade de fazer uma distinção clara entre os dois tipos neste estudo, especialmente na área da saúde.

\section{Resultados e discussão}

Nesta seção, são apresentados os resultados do estudo de acordo com os objetivos: a) identificar o modelo de acesso; b) descrever as características institucionais das revistas; e c) apontar os recursos tecnológicos utilizados.

A representação dos países latino-americanos nas bases de dados estudadas é mínima, o Sciverse Scopus ${ }^{1}$ tem um total de 19.000 títulos e a América latina responde por 2,3\% dos títulos indexados nessa base. Em segundo lugar está a Thompson Reuters ISI Web of Science ${ }^{2}$ com 10.000, sendo que $2,2 \%$ estão registados em países latino-americanos (ABADAL, 2012). Cumpre destacar a semelhança de representaçao em ambas as bases, mesmo que a SCOPUS afirme ter uma melhor cobertura das Ciências Sociais. A justificativa da escolha destas bases como corpus de pesquisa é que permitem comparações, com abrangência internacional, por países, uma vez que a informação sobre o tipo de acesso não está detalhada nas bases.

Do total geral de 556 títulos, 9 títulos não foram localizados no período da coleta dos dados e 11 estavam em acesso restrito; 536 títulos foram encontrados e estão em Acesso Aberto e compõem o corpus do estudo. Isso representa que $98 \%$ dos periódicos válidos da amostra estão em Acesso Aberto. Esse dado corrobora a literatura, que afirma que a América Latina como um todo está muito à frente de todas as outras regiões do mundo, em termos de quantidade de periódicos em Acesso Aberto (ALPERIN; FISCHMAN; WILLINSKY, 2008; TERRA-FIGARI, 2008; YUNTA, 2010).

Os periódicos em acesso restrito são: a) quatro na Colômbia, nas áreas Multidisciplinary, Materials Science, Social Sciences e Arts and Humanities; b) quatro no México, na Engineering, Psychology, Medicine e

${ }^{1}$ SciVerse Scopus é o maior banco de dados de resumo e citações, contendo tanto peer-reviewed literatura de pesquisa e fontes Web de qualidade. Possui Cerca de 19.500 títulos de 5.000 editoras em todo o mundo. Disponível em: < http://www.info.sciverse.com/scopus>. Acesso em: 27 mar. 2012.

${ }^{2}$ Thompson Reuters ISI Web of Science é uma plataforma de pesquisa para a informação em Ciências, Ciências Sociais, Artes e Humanidades. Conteúdo Authoritative multidisciplinar abrange mais de 12.000 dos periódicos de maior impacto em todo o mundo, incluindo revistas de acesso aberto e mais de 150.000 procedimentos de conferências. Disponível em: <http://thomsonreuters.com/>. Acesso em: 27 mar. 2012. 
Mathematics; c) um no Brasil, na Engineering; e d) dois no Chile, na Economics e Social Sciences.

\subsection{Características institucionais}

Muitos títulos que estão indexados no Scopus também estão no ISI, do total de 536 títulos, 92,5\% (496) estão no Scopus e 41,6\% (223) estão no ISI, o grau de solapamento nas duas bases é de 34,5\% (185). Yunta (2010) explica que a base Scopus possui maior cobertura documental, por apresentar uma seleção menos restritiva em relação a ISI. Comparando os periódicos latino-americanos do estudo de Yunta (2010), verifica-se um aumento de 14,3\% (32) no número de periódicos indexados no ISI em 2011.

As especificidades da comunicaçao científica da região, a baixa representatividade mundial nas bases internacionais e o alto índice de títulos de qualidade em Acesso aberto indicam que o esforço editorial das comunidades científicas está sendo subvencionado por instituições cuja fonte de receita principal não é a editoração e comercialização de revistas ou artigos científicos. A identificação dessas instituições fornece a base para o entendimento do notável índice de $98 \%$ de títulos em Acesso Aberto, muito superior a todos os indicadores encontrados na literatura sobre outros países (ABADAL et al., 2010), mas coerente com os estudos sobre os países latino-americanos (DELGADO, 2011; YUNTA, 2010).

A análise das características das entidades editoriais responsáveis pelos títulos foi baseada nos seguintes dados: definição da entidade editorial, identificação da área do conhecimento, do ano de criação e da periodicidade de cada revista. Conforme explica Muller (2011), a expressão "entidades editoras" foi adotada para designar a função de publicador (publisher). Quando as informações necessárias não estavam disponíveis na página das revistas, foi consultada a base Ulrich.

Tabela 1 - Entidades editoras

\begin{tabular}{l|c|c|c|c|c|c|c|c|c|c|c|c|c}
\hline & ARG & BR & CHL & COL & CRI & CUB & ECU & MEX & PER & URY & VEM & Total & $\%$ \\
\hline Associações & $\mathbf{2 1}$ & $\mathbf{9 5}$ & $\mathbf{2 0}$ & $\mathbf{9}$ & 0 & 4 & 1 & $\mathbf{2 3}$ & 1 & 1 & $\mathbf{1 1}$ & $\mathbf{1 8 6}$ & $\mathbf{3 4 , 7 \%}$ \\
\hline $\begin{array}{l}\text { Editoras } \\
\text { comerciais }\end{array}$ & 2 & 6 & 1 & - & - & - & - & 4 & - & - & 1 & $\mathbf{1 4}$ & $\mathbf{2 , 6 \%}$ \\
\hline Governo & 1 & 4 & 2 & - & - & $\mathbf{1 4}$ & - & - & - & - & 1 & $\mathbf{2 2}$ & $\mathbf{4 , 1 \%}$ \\
\hline $\begin{array}{l}\text { Institutos de } \\
\text { pesquisas }\end{array}$ & 3 & 25 & 4 & 5 & - & 2 & - & $\mathbf{1 9}$ & - & - & 2 & $\mathbf{6 0}$ & $\mathbf{1 1 , 2 \%}$ \\
\hline Universidades & $\mathbf{9}$ & $\mathbf{1 0 8}$ & $\mathbf{4 6}$ & $\mathbf{2 7}$ & $\mathbf{2}$ & - & - & $\mathbf{2 5}$ & 1 & - & $\mathbf{2 3}$ & $\mathbf{2 4 1}$ & $\mathbf{4 5 , 0 \%}$ \\
\hline Não Informado & 5 & 3 & - & - & - & 1 & 1 & 2 & - & - & 1 & $\mathbf{1 3}$ & $\mathbf{2 , 4 \%}$ \\
\hline Total & $\mathbf{4 1}$ & $\mathbf{2 4 1}$ & $\mathbf{7 3}$ & $\mathbf{4 1}$ & $\mathbf{2}$ & $\mathbf{2 1}$ & $\mathbf{2}$ & $\mathbf{7 3}$ & $\mathbf{2}$ & $\mathbf{1}$ & $\mathbf{3 9}$ & $\mathbf{5 3 6}$ & $\mathbf{1 0 0 , 0 \%}$ \\
\hline \multicolumn{1}{c}{$\%$} & $\mathbf{7 , 6 \%}$ & $\mathbf{4 5 , 0 \%}$ & $\mathbf{1 3 , 6 \%}$ & $\mathbf{7 , 6 \%}$ & $\mathbf{0 , 4 \%}$ & $\mathbf{3 , 9 \%}$ & $\mathbf{0 , 4 \%}$ & $\mathbf{1 3 , 6 \%}$ & $\mathbf{0 , 4 \%}$ & $\mathbf{0 , 2} \%$ & $\mathbf{7 , 3 \%}$ & $\mathbf{1 0 0 , 0} \%$ & \\
\hline
\end{tabular}

Fonte: Dados da pesquisa.

Verifica-se, na tabela, que as universidades são responsáveis pelo maior índice de títulos, com 45\% (241) do total, seguido pelas Associações, com 34,7\% (186). Destaque para os Institutos de Pesquisa no México e para o Governo de Cuba. Em seguida, estão os Institutos de pesquisa, com $11,2 \%(60)$, e o Governo, com $4,1 \%$ (22) de revistas. 0 campo "não informado" apresenta 2,4\% (13) e com apenas 2,6\% (14) títulos, estão as editoras comerciais. 
Ainda, analisando a Tabela 2, pode-se observar que, no Brasil, as universidades são responsáveis por 20\% (108) dos títulos editados na região; em segundo lugar está o Chile, com 8,6\% (46); e, em terceiro, a Colômbia, apresentando 5\% (27) dos títulos. Destaque, ainda, para a atuação das associações no Brasil, na Argentina e no México

Como explica Badat (2009, p. 11), as universidades estão se tornando, cada vez mais, produtoras de conhecimento e assumem grande importância no contexto científico. Cetto e Alonso Gamboa (2011) ainda expõem que as publicações na América Latina permanecem fragmentadas a nível nacional e as universidades vêm ganhando popularidade nos últimos anos, o que chamam de elite de pesquisa da universidade.

Garrido e Rodrigues (2010) e Rodrigues e Fachin (2010) analisam a criação de Portais de Periódicos Científicos por parte das universidades brasileiras, nos quais a instituição se responsabiliza pelas questões técnicas, da segurança dos dados, da migração das versões das plataformas e oferece suporte aos editores de cada revista, caracterizando-se como uma "meta-editora", que atende a todos os títulos, que continuam responsáveis pela seleção e editoração do conteúdo.

Yunta (2010, p. 11) explica o crescimento da publicação científica em países ibero-americos:

Claramente, o Brasil e a Espanha são os países da comunidade ibero-americana que situam suas publicações em uma certa posição intermediária dentro do panorama internacional. É importante destacar que a Espanha conseguiu subir a quinta posição no SSCI, quando a sua posição antes das novas adições era praticamente invisível. O Brasil destaca-se especialmente por seu potencial dentro do SCIE, onde ele está à frente da Espanha. Outros países, como Chile e México, estão em uma zona intermediária muito menos relevante.

O crescimento dos títulos latino-americanos acompanha a expansão do Acesso Aberto. No Brasil, tem-se 241 títulos de periódicos qualificados nessa condição. Comparado ao total global é pouco, mas a quantidade de títulos em Acesso Aberto, em relaçao ao total de cada país, é digna de nota, confirmando estudos que usam indexadores regionais como amostra (TRONCOSO, 2011).

É necessário distinguir as diferentes áreas do conhecimento, pois as especificidades editoriais são diferentes em cada área. A Tabela 2, a seguir, indica as entidades responsáveis por cada área. 
Tabela 2 - Entidades editoras por áreas do conhecimento

\begin{tabular}{|c|c|c|c|c|c|c|c|c|}
\hline & Associações & \begin{tabular}{|c} 
Editoras \\
Comerciais
\end{tabular} & Governo & $\begin{array}{c}\text { Instituto de } \\
\text { pesqusia }\end{array}$ & Universidades & \begin{tabular}{|c|} 
Não \\
Informado
\end{tabular} & Total & $\%$ \\
\hline $\begin{array}{l}\text { Agricultural and Biological } \\
\text { Sciences }\end{array}$ & 36 & 1 & 2 & 15 & 47 & 4 & 105 & $19,6 \%$ \\
\hline Arts and Humanities & 2 & - & - & 5 & 29 & - & 36 & $6,7 \%$ \\
\hline $\begin{array}{l}\text { Biochemistry, Genetics and } \\
\text { Molecular Biology }\end{array}$ & 5 & 1 & - & 3 & 2 & 1 & 12 & $2,2 \%$ \\
\hline $\begin{array}{l}\text { Business, Management and } \\
\text { Accounting }\end{array}$ & 4 & - & - & - & 7 & - & 11 & $2,1 \%$ \\
\hline Chemical Engineering & 2 & - & 1 & 1 & 1 & - & 5 & $0,9 \%$ \\
\hline Chemistry & 5 & - & - & - & 4 & - & 9 & $1,7 \%$ \\
\hline Computer Science & - & - & - & - & - & - & 0 & $0,0 \%$ \\
\hline Decision Sciences & 1 & - & - & - & - & - & 1 & $0,2 \%$ \\
\hline Dentistry & 2 & 2 & - & - & 4 & - & 8 & $1,5 \%$ \\
\hline $\begin{array}{l}\text { Earth and Planetary } \\
\text { Sciences }\end{array}$ & 6 & - & 1 & 4 & 11 & - & 22 & $4,1 \%$ \\
\hline $\begin{array}{l}\text { Economics, Econometrics } \\
\text { and Finance }\end{array}$ & - & 1 & 1 & 6 & 10 & 1 & 19 & $3,5 \%$ \\
\hline Energy & - & - & - & 1 & - & - & 1 & $0,2 \%$ \\
\hline Engineering & 9 & - & - & 2 & 11 & - & 22 & $4,1 \%$ \\
\hline Environmental Science & 5 & - & - & - & 7 & 1 & 13 & $2,4 \%$ \\
\hline Health Professions & 3 & 1 & - & - & - & - & 4 & $0,7 \%$ \\
\hline $\begin{array}{l}\text { Immunology and } \\
\text { Microbiology }\end{array}$ & 5 & 1 & - & 1 & 1 & - & 8 & $1,5 \%$ \\
\hline Materials Science & 3 & - & - & - & 3 & - & 6 & $1,1 \%$ \\
\hline Mathematics & - & - & - & - & 3 & 1 & 4 & $0,7 \%$ \\
\hline Medicine & 82 & 18 & 2 & 12 & 24 & 3 & 141 & $26,3 \%$ \\
\hline Multidisciplinary & 2 & - & - & - & - & - & 2 & $0,4 \%$ \\
\hline Neuroscience & - & - & - & 1 & 1 & - & 2 & $0,4 \%$ \\
\hline Nursing & 1 & - & - & - & 7 & - & 8 & $1,5 \%$ \\
\hline $\begin{array}{l}\text { Pharmacology, Toxicology } \\
\text { and Pharmaceutics }\end{array}$ & 1 & 1 & - & - & 5 & - & 7 & $1,3 \%$ \\
\hline Physics and Astronomy & 4 & - & - & - & - & - & 4 & $0,7 \%$ \\
\hline Psychology & 2 & - & 1 & 1 & 13 & - & 17 & $3,2 \%$ \\
\hline Social Sciences & 5 & 1 & 1 & 8 & 44 & 2 & 61 & $11,4 \%$ \\
\hline Veterinary & 1 & - & - & - & 7 & - & 8 & $1,5 \%$ \\
\hline Total & 186 & 27 & 9 & 60 & 241 & 13 & 536 & $100,0 \%$ \\
\hline$\%$ & $34,7 \%$ & $5,0 \%$ & $1,7 \%$ & $11,2 \%$ & $45,0 \%$ & $2,4 \%$ & & \\
\hline
\end{tabular}

Fonte: Dados da pesquisa.

O destaque dessa tabela é a identificação das insituições responsáveis por diferentes áreas do conhecimento. Estudos de periódicos que não levem em consideração as áreas do conhecimento apresentam limitações nas análises, nos casos dos títulos em Acesso Aberto, pois as áreas tem especificidades essenciais ao entendimento de como se comporta cada comunidade.

A análise da representação das áreas do conhecimento por país indica que as três áreas que mais concentram periódicos são: Medicine, com 26,3\% (141), a maioria publicada pelas Associações; Agricultural and Biological Sciences, com 19,6\% (105) , com equilíbrio de distribuição entre as Universidades e Associações; e Social Sciences, com 11,4\% (61), com predominância das Universidades. 
Figura 1 - Distribuição por áreas do conhecimento

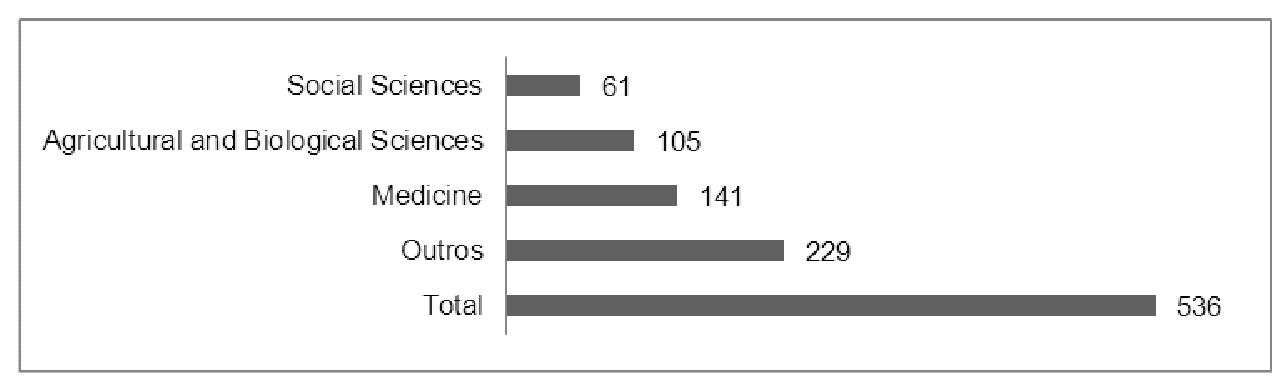

Fonte: Dados da pesquisa.

A Figura 1 também indica que, das 27 áreas do Scopus, três concentram $57,3 \%$ dos periódicos, sendo as 24 outras áreas juntas responsáveis por $42,7 \%$ do total.

A distribuição dos títulos em cada área do conhecimento por país, indica a localização das comunidades científicas articuladas o suficiente para manter os títulos. A Tabela 3, a seguir, mostra o resultado.

Tabela 3 - Distribuição das áreas do conhecimento por país

\begin{tabular}{|c|c|c|c|c|c|c|c|c|c|c|c|c|c|}
\hline & ARG & BR & CHL & COL & \begin{tabular}{|l|} 
CRI \\
\end{tabular} & CUB & ECU & MEX & PER & URY & VEM & Total & $\%$ \\
\hline $\begin{array}{l}\text { Agricultural and } \\
\text { Biological Sciences }\end{array}$ & 11 & 53 & 10 & 8 & 2 & 2 & - & 11 & - & - & 8 & 105 & $19,6 \%$ \\
\hline Arts and Humanities & 1 & 12 & 14 & 1 & - & - & - & 3 & 1 & - & 4 & 36 & $6,7 \%$ \\
\hline $\begin{array}{l}\text { Biochemistry, Genetics } \\
\text { and Molecular Biology }\end{array}$ & 3 & 5 & 1 & - & - & 1 & - & 1 & - & - & 1 & 12 & $2,2 \%$ \\
\hline $\begin{array}{l}\text { Business, Management } \\
\text { and Accounting }\end{array}$ & - & 4 & 2 & 3 & - & - & - & - & - & - & 2 & 11 & $2,1 \%$ \\
\hline Chemical Engineering & 1 & 4 & - & - & - & - & - & - & - & - & - & 5 & $0,9 \%$ \\
\hline Chemistry & 1 & 4 & 1 & 1 & - & - & - & 2 & - & - & - & 9 & $1,7 \%$ \\
\hline Computer Science & - & - & - & - & - & - & - & - & - & - & - & 0 & $0,0 \%$ \\
\hline Decision Sciences & - & 1 & - & - & - & - & - & - & - & - & - & 1 & $0,2 \%$ \\
\hline Dentistry & - & 6 & - & - & - & 1 & - & - & - & - & 1 & 8 & $1,5 \%$ \\
\hline $\begin{array}{l}\text { Earth and Planetary } \\
\text { Sciences }\end{array}$ & 1 & 10 & 2 & 1 & - & - & - & 7 & - & - & 1 & 22 & $4,1 \%$ \\
\hline $\begin{array}{l}\text { Economics, } \\
\text { Econometrics and } \\
\text { Finance }\end{array}$ & 2 & 6 & 3 & 4 & - & - & - & 4 & - & - & - & 19 & $3,5 \%$ \\
\hline Energy & - & - & - & 1 & - & - & - & - & - & - & - & 1 & $0,2 \%$ \\
\hline Engineering & - & 8 & 5 & 3 & - & - & - & 2 & - & 1 & 3 & 22 & $4,1 \%$ \\
\hline Environmental Science & 1 & 8 & 3 & - & - & - & - & 1 & - & - & - & 13 & $2,4 \%$ \\
\hline Health Professions & - & 3 & - & - & - & 1 & - & - & - & - & - & 4 & $0,7 \%$ \\
\hline $\begin{array}{l}\text { Immunology and } \\
\text { Microbiology }\end{array}$ & - & 3 & 1 & - & - & 2 & - & 1 & - & - & 1 & 8 & $1,5 \%$ \\
\hline Materials Science & - & 6 & - & - & - & - & - & - & - & - & & 6 & $1,1 \%$ \\
\hline Mathematics & 1 & - & 1 & 1 & - & - & - & - & - & - & 1 & 4 & $0,7 \%$ \\
\hline Medicine & 16 & 54 & 15 & 10 & - & 11 & 1 & 25 & 1 & - & 8 & 141 & $26,3 \%$ \\
\hline Multidisciplinary & - & 1 & - & - & - & - & - & - & - & - & 1 & 2 & $0,4 \%$ \\
\hline Neuroscience & - & 1 & - & - & - & - & - & 1 & - & - & - & 2 & $0,4 \%$ \\
\hline Nursing & - & 5 & 1 & 1 & - & 1 & - & - & - & - & - & 8 & $1,5 \%$ \\
\hline $\begin{array}{l}\text { Pharmacology, } \\
\text { Toxicology and } \\
\text { Pharmaceutics }\end{array}$ & - & 4 & 1 & - & - & 1 & - & 1 & - & - & - & 7 & $1,3 \%$ \\
\hline Physics and Astronomy & - & 2 & - & - & - & - & - & 2 & - & - & - & 4 & $0,7 \%$ \\
\hline Psychology & 2 & 10 & 1 & 4 & - & - & - & - & - & - & - & 17 & $3,2 \%$ \\
\hline Social Sciences & 1 & 27 & 11 & 3 & - & 1 & 1 & 11 & - & - & 6 & 61 & $11,4 \%$ \\
\hline Veterinary & - & 5 & 1 & - & - & - & - & 1 & - & - & 1 & 8 & $1,5 \%$ \\
\hline Total & 41 & 242 & 73 & 41 & 2 & 21 & 2 & 73 & 2 & 1 & 38 & 536 & $100,0 \%$ \\
\hline$\%$ & $7,6 \%$ & $45,1 \%$ & $13,6 \%$ & $7,6 \%$ & $0,4 \%$ & $3,9 \%$ & $0,4 \%$ & $13,6 \%$ & $0,4 \%$ & $0,2 \%$ & $7,1 \%$ & & \\
\hline
\end{tabular}

Fonte: Dados da pesquisa. 
Nota-se que a Medicine é a área com maior número de títulos em todos os países com 26,3\% (141) do total, exceto na Costa Rica, Uruguai, Equador e Peru. O Brasil possui a maior quantidade de títulos na área da Medicine com 10,1\% (54), México com 4,7\% (25), Argentina apresenta $3 \%$ (16) de títulos, o Chile 2,8\% (15), Cuba 2,1\% (11), a Colômbia 1,9\% (10) e a Venezuela 1,5\% (9).

Em segundo lugar está a Agricultural and Biological Sciences, com $9,9 \%$ (53) dos títulos no Brasil, em quantidade semelhante à Medicine; $2,1 \%$ (11) estão na Argentina e no México; valores iguais se apresentam na Colômbia e na Venezuela, com 1,5\% (8) títulos. O total da área Agricultural and Biological Sciences é de 19,6\%, isto é, 105 títulos.

Em terceiro lugar está a Social Sciences com 11,4\% (61), já com um percentual nitidamente inferior em relação as duas primeiras, a maioria dos títulos está no Brasil, com 5\% (27); e México e Chile, com $2,1 \%$ (11) cada um.

A questão do idioma torna-se relevante no cenário digital. Quanto mais idiomas diferentes o periódico aceita, maior o grau de internacionalização. Alguns títulos publicam apenas em inglês e outros providenciam edições bilíngues.

Para a análise dos idiomas, foram pesquisadas as informações necessárias, no link "instrução aos autores", no "sobre" da própria revista analisada ou no Ulrich. Nessa coleta, os idiomas se sobrepuseram, por isso o total foi maior que o número de títulos, pois foi considerada a quantidade de idiomas que os periódicos aceitam em seus artigos.

Tabela 4 - Idioma dos artigos

\begin{tabular}{l|c|c|c|c|c|c|c|c|c|c|c|c|c}
\hline & & & & & & & & & & & & & \\
\hline & ARG & BR & CHL & COL & CRI & CUB & ECU & MEX & PER & URY & VEM & Total & $\%$ \\
\hline Espanhol & 35 & 69 & 60 & 41 & 2 & 20 & 2 & 69 & 2 & 1 & 39 & 340 & $36,0 \%$ \\
\hline Português & 7 & 201 & 6 & 12 & - & 1 & - & 1 & 1 & - & 16 & 245 & $25,9 \%$ \\
\hline Inglês & 26 & 177 & 43 & 32 & 2 & 3 & - & 39 & - & - & 23 & 345 & $36,5 \%$ \\
\hline Francês & 1 & 2 & 1 & 1 & - & - & - & 2 & - & - & 4 & 11 & $1,2 \%$ \\
\hline Alemão & - & - & - & - & - & - & - & - & - & - & 1 & 1 & $0,1 \%$ \\
\hline Italiano & - & - & - & 1 & - & - & - & - & - & - & 2 & 3 & $0,3 \%$ \\
\hline Total & 69 & 449 & 110 & 87 & 4 & 24 & 2 & 111 & 3 & 1 & 85 & 945 & $100,0 \%$ \\
\hline \multicolumn{1}{c}{$\%$} & $7,3 \%$ & $47,5 \%$ & $11,6 \%$ & $9,2 \%$ & $0,4 \%$ & $2,5 \%$ & $0,2 \%$ & $11,7 \%$ & $0,3 \%$ & $0,1 \%$ & $9,0 \%$ & $100,0 \%$ & \\
\hline
\end{tabular}

Fonte: Dados da pesquisa.

Observando a Tabela 4, verifica-se que os 536 títulos aceitam mais de um idioma, critério necessário para a indexação em bases internacionais, como é o caso da amostra utilizada nesse trabalho. O inglês é a língua que predomina em 36,5\% (345) dos títulos, em segundo lugar está o espanhol, com 36\% (340). O português apresenta 25,9\% (245). Venezuela e Colômbia possuem, cada um, um periódico que aceita artigos também em alemão. Em italiano, dois títulos são mencionados na Venezuela.

O Acesso Aberto elimina as barreiras geográficas, mas o idioma permanece como uma questão importante para alcançar o cenário global e se mantém como limitação para editores, avaliadores, autores e leitores. 
A questão da migração dos títulos originalmente impressos para o cenário digital é relevante, pois $100 \%$ dos periódicos estudados estão online, o que permite quantificar o grau de adoção da versão eletrônica como universal nesse contexto, tornando ultrapassada a discussão sobre a aceitação do digital e a qualidade dos títulos. Para identificar o ano de criação das revistas, pesquisou-se, no site Ulrich, pelos títulos e, no próprio site da revista, o ano do primeiro fascículo disponível.

Tabela 5 - Ano de criação dos periódicos

\begin{tabular}{l|c|c|c|c|c|c|c|c|c|c|c|c|c}
\hline & ARG & BR & CHL & COL & CRI & CUB & ECU & MEX & PER & URY & VEM & Total & $\%$ \\
\hline 1860 à 1950 & 12 & 23 & 11 & 3 & - & 2 & - & 15 & - & - & 5 & 71 & $13,2 \%$ \\
\hline 1951 à 1960 & 3 & 12 & 1 & 1 & 2 & - & - & 10 & - & - & 2 & 31 & $5,8 \%$ \\
\hline 1961 à 1970 & 3 & 16 & 10 & 3 & - & 6 & - & 8 & - & - & 6 & 52 & $9,7 \%$ \\
\hline 1971 à 1980 & 5 & 40 & 13 & 4 & - & 1 & - & 9 & - & - & 7 & 79 & $14,7 \%$ \\
\hline 1981 à 1990 & 5 & 35 & 11 & 13 & - & 7 & - & 12 & - & - & 7 & 90 & $16,8 \%$ \\
\hline 1991 à 2000 & 11 & 62 & 16 & 11 & - & 4 & 2 & 10 & 2 & 1 & 9 & 128 & $23,9 \%$ \\
\hline 2001 à 2010 & 2 & 53 & 11 & 6 & - & 1 & - & 9 & - & - & 3 & 85 & $15,9 \%$ \\
\hline Total & 41 & 241 & 73 & 41 & 2 & 21 & 2 & 73 & 2 & 1 & 39 & 536 & $100,0 \%$ \\
\hline
\end{tabular}

Fonte: Dados da pesquisa.

A análise do ano de criação permite identificar os títulos que nasceram no formato impresso e que migraram para o digital. A década com maior crescimento no número de periódicos foi a de 90 , com $23,9 \%$ (128) dos títulos. Foi nessa época, que surgiram as tecnologias da comunicação e informação, que facilitaram a criação de novos títulos, 39,7\% (213) dos títulos iniciaram entre 1991 e 2010. Cumpre destacar que a disponibilidade de tecnologia não é fator responsável pela qualidade das revistas: o crescimento das universidades, especialmente da Pósgraduação, a internacionalização em várias áreas e outros aspectos que fogem ao escopo deste trabalho, interferem na situação. A partir dos anos 90, a Internet se populariza e as revistas científicas digitais ocupam um lugar central nos modos de organização e troca de informações entre as comunidades científicas e acadêmicas (SANTOS JUNIOR, 2010; SILVA; SANTOS; PRAZERES, 2011). Após a década de 90, observa-se que o crescimento diminuiu, apenas $15,9 \%$ (85) dos novos periódicos surgem no século XXI, e uma possível explicação para esse fenômeno é que os periódicos recentes estão em processo de consolidação e, ainda, não atendem às exigências dos indexadores.

A análise dos periódicos mostra a adoção praticamente universal do modelo Acesso Aberto nos países latino-americanos, devido principalmente ao esforço das universidades em todas as áreas e das associações profissionais e científicas, em especial na área da Medicina. Os resultados nos levam a crer que quando as revistas migraram para o formato digital adotaram simultaneamente 0 modelo Acesso Aberto (GAMBO; ISLAS, 2005; MARCONDES et al., 2004). 
As discussões sobre modelos de negócios na migração de periódicos para o Acesso Aberto se referem a empresas editoriais de caráter comercial e detalham equipes profissionais de editoração, tecnológica, financeira, marketing e outras (VILLARROYA et al., 2012). A aplicação desses estudos nos países latinos se torna difícil em função do entendimento por parte das entidades editoriais e pesquisadores de que os periódicos não necessariamente devem gerar lucro, devem gerar essencialmente prestígio.

O prestígio do periódico contribui para a visibilidade da instituição, o que pode criar condições de obter verbas por meio de editais públicos, conseguir mais sócios, ter mais e melhores alunos, mais pesquisadores de renome e outros benefícios. O compartilhamento de condições estruturais com a instituição responsável, que tem outro tipo de atividade como principal que não a editorial, gera questionamentos sobre o padrão dos recursos específicos dos periódicos.

\subsection{Recursos tecnológico}

O uso de softwares e plataformas de editoração científica são elementos essenciais para o processo de editoração e para a visibilidade dos periódicos e indicam a escolha do editor sobre as várias alternativas existentes. Das revistas analisadas, 69\% (370) estão no SciELO, mensurando a já conhecida importância da chamada biblioteca na América Latina.

O uso pode ser exclusivo ou consorciado com outras alternativas: a maioria, 37,3\% (200) dos periódicos, usa apenas a plataforma SCiELO, na sequência tem-se novamente a SciELO, usado simultaneamente com plataforma própria, com 25,7\% (138) dos periódicos. Em terceiro, verifica-se o uso exclusivo de plataforma própria, com 20,3\% (109) dos títulos. O Open Journal System (OJS) é utilizado no Brasil por 8,8\% (47) dos periódicos que utilizam a plataforma simultaneamente com outras alternativas. No total geral dos países, verifica-se a mesma quantidade, $8,8 \%$ (47) de títulos que usam somente o OJS.

Tabela 6 - Distribuição das plataformas por país

\begin{tabular}{|c|c|c|c|c|c|c|c|c|c|c|c|c|c|}
\hline \multicolumn{14}{|c|}{ País x Plataforma } \\
\hline & ARG & $\mathrm{BR}$ & $\mathrm{CHL}$ & $\mathrm{COL}$ & CRI & CUB & ECU & MEX & PER & URY & VEM & Total & $\%$ \\
\hline OJS & - & 27 & 3 & 12 & - & - & - & 4 & - & - & 1 & 47 & $8,8 \%$ \\
\hline Própria & 15 & 23 & 6 & 16 & - & 2 & 2 & 37 & 1 & 1 & 6 & 109 & $20,3 \%$ \\
\hline Outra & - & - & - & - & - & - & - & 4 & - & - & - & 4 & $0,7 \%$ \\
\hline OJS e Própria & - & 3 & - & 2 & - & - & - & - & - & - & 1 & 6 & $1,1 \%$ \\
\hline SciELo & 7 & 73 & 59 & 7 & 2 & 19 & - & 26 & - & - & 7 & 200 & $37,3 \%$ \\
\hline OJS e SciELo & 2 & 17 & - & 1 & - & - & - & 1 & - & - & 6 & 27 & $5,0 \%$ \\
\hline SciELo e Própria & 15 & 98 & 5 & 3 & - & - & - & 1 & 1 & - & 15 & 138 & $25,7 \%$ \\
\hline $\begin{array}{l}\text { SciELo, OJS e } \\
\text { Própria }\end{array}$ & 2 & - & - & - & - & - & - & - & - & - & 3 & 5 & $0,9 \%$ \\
\hline Total & 41 & 241 & 73 & 41 & 2 & 21 & 2 & 73 & 2 & 1 & 39 & 536 & $100 \%$ \\
\hline Todos SciELo & 370 & & & & & & & & & & & & \\
\hline
\end{tabular}

Fonte: Dados da pesquisa. 
Observando a Tabela 6, verifica-se que a Colômbia possui 3\% (16) dos títulos na plataforma própria e 2,2\% (12) na plataforma OJS. O México é o país que mais apresenta títulos em plataforma própria, com $6,9 \%$ (37) do total da região.

A SCiELO é uma biblioteca eletrônica, um modelo cooperativo de publicação de revistas científicas, que abrange uma coleção selecionada de títulos. É uma iniciativa conceituada, presente em 15 países latinoamericanos, são eles: Argentina, Brasil, Bolívia, Chile, Colômbia, Costa Rica, Cuba, Espanha, México, Paraguai, Peru, Portugal, África do Sul, Uruguai e Venezuela. A SciElo possui 935 revistas e 39,6\% (370) são títulos latino-americanos (ARELLANO, 2011; FERREIRA, 2008; SCIELO, 2012; TERRA-FIGARI, 2008).

A Tabela 7, a seguir, mostra a distribuição das diversas plataformas nas áreas do conhecimento.

Tabela 7 - Distribuição das plataformas nas áreas do conhecimento

\begin{tabular}{|c|c|c|c|c|c|c|c|c|c|c|}
\hline & OJS & Própria & Outra & $\begin{array}{l}\text { OJS e } \\
\text { Própria }\end{array}$ & Scielo & $\begin{array}{l}\text { OJS e } \\
\text { Scielo }\end{array}$ & $\begin{array}{c}\text { Scielo } \\
\text { e } \\
\text { Própria }\end{array}$ & $\begin{array}{c}\text { Scielo, } \\
\text { OJS e } \\
\text { Própria }\end{array}$ & Total & $\%$ \\
\hline Agricultural and Biological Sciences & 11 & 20 & - & 2 & 31 & 5 & 34 & 2 & 105 & $19,6 \%$ \\
\hline Arts and Humanities & 3 & 7 & - & - & 18 & 3 & 5 & - & 36 & $6,7 \%$ \\
\hline $\begin{array}{l}\text { Biochemistry, Genetics and Molecular } \\
\text { Biology }\end{array}$ & 3 & 1 & - & - & 4 & - & 4 & - & 12 & $2,2 \%$ \\
\hline Business, Management and Accounting & 3 & 2 & - & - & 2 & - & 4 & - & 11 & $2,1 \%$ \\
\hline Chemical Engineering & - & 2 & - & - & 1 & - & 2 & - & 5 & $0,9 \%$ \\
\hline Chemistry & 1 & 2 & - & - & 4 & - & 2 & - & 9 & $1,7 \%$ \\
\hline Computer Science & - & - & - & - & - & - & - & - & 0 & $0,0 \%$ \\
\hline Decision Sciences & - & - & - & - & 1 & - & - & - & 1 & $0,2 \%$ \\
\hline Dentistry & 1 & 2 & - & - & 3 & - & 2 & - & 8 & $1,5 \%$ \\
\hline Earth and Planetary Sciences & 2 & 6 & - & - & 5 & 3 & 6 & - & 22 & $4,1 \%$ \\
\hline Economics, Econometrics and Finance & - & 7 & - & - & 6 & 2 & 4 & - & 19 & $3,5 \%$ \\
\hline Energy & - & - & - & - & 1 & - & - & - & 1 & $0,2 \%$ \\
\hline Engineering & 3 & 4 & - & 1 & 7 & 4 & 3 & - & 22 & $4,1 \%$ \\
\hline Environmental Science & 2 & 3 & - & 1 & 6 & - & 1 & - & 13 & $2,4 \%$ \\
\hline Health Professions & - & - & - & - & 1 & - & 3 & - & 4 & $0,7 \%$ \\
\hline Immunology and Microbiology & - & 1 & - & - & 5 & - & 2 & - & 8 & $1,5 \%$ \\
\hline Materials Science & - & 2 & - & - & - & - & 4 & - & 6 & $1,1 \%$ \\
\hline Mathematics & - & 1 & - & 1 & 1 & - & 1 & - & 4 & $0,7 \%$ \\
\hline Medicine & 5 & 36 & 4 & - & 57 & 2 & 36 & 1 & 141 & $26,3 \%$ \\
\hline Multidisciplinary & - & - & - & - & - & - & 2 & - & 2 & $0,4 \%$ \\
\hline Neuroscience & - & - & - & - & 1 & 1 & - & - & 2 & $0,4 \%$ \\
\hline Nursing & 2 & - & - & - & 2 & - & 4 & - & 8 & $1,5 \%$ \\
\hline $\begin{array}{l}\text { Pharmacology, Toxicology and } \\
\text { Pharmaceutics }\end{array}$ & 1 & 1 & - & - & 3 & - & 2 & - & 7 & $1,3 \%$ \\
\hline Physics and Astronomy & - & - & - & - & 2 & 1 & 1 & - & 4 & $0,7 \%$ \\
\hline Psychology & 3 & 2 & - & - & 8 & 1 & 3 & - & 17 & $3,2 \%$ \\
\hline Social Sciences & 6 & 9 & - & - & 28 & 5 & 12 & 1 & 61 & $11,4 \%$ \\
\hline Veterinary & 1 & 1 & - & 1 & 3 & - & 1 & 1 & 8 & $1,5 \%$ \\
\hline Total & 47 & 109 & 4 & 6 & 200 & 27 & 138 & 5 & 536 & $100,0 \%$ \\
\hline$\%$ & $8,8 \%$ & $20,3 \%$ & $0,7 \%$ & $1,1 \%$ & $37,3 \%$ & $5,0 \%$ & $25,7 \%$ & $0,9 \%$ & & \\
\hline
\end{tabular}

Fonte: Dados da pesquisa.

Observando a Tabela 7, verifica-se que muitos periódicos optam por ter seus títulos em mais de uma plataforma, possivelmente por facilidades diferenciadas em cada uma. Ainda assim, é possível observar a 
importância da plataforma SciELO em todas as áreas, pois soma $68,9 \%$ da amostra.

O diálogo científico está mais estruturado na região onde há maior oferta de títulos (WITHLEY 1984; ZIMAN, 1979; GUÉDON, 2001), e é possível identificar a Medicina, a Agronomia, Ciências Biológicas e Ciências Sociais. As áreas que tem menos periódicos podem estar em outras situações de espaço de diálogo ou valorizam outros canais de comunicação (livros ou eventos) que reconheçam poucos periódicos e estes estejam concentrados em outros países, mas a comprovação foge do escopo do trabalho.

Como a quantidade de títulos é um indicador da existência de diálogo científico em determinada área, a periodicidade dos títulos indica a quantidade e velocidade desse diálogo. Os dados apresentam títulos, desde os mensais, com 4,1\% (22) dos títulos, até os anuais, com 2,6\% (14) dos títulos.

Tabela 8 - Disposição das áreas pela periodicidade

\begin{tabular}{|c|c|c|c|c|c|c|c|c|}
\hline & Mensal & Bim. & Trim. & Quad. & Sem. & Anual & Total & $\%$ \\
\hline Agricultural and Biological Sciences & 6 & 11 & 45 & 12 & 28 & 3 & 105 & $19,6 \%$ \\
\hline Arts and Humanities & - & - & 3 & 7 & 23 & 3 & 36 & $6,7 \%$ \\
\hline $\begin{array}{l}\text { Biochemistry, Genetics and Molecular } \\
\text { Biology }\end{array}$ & 1 & 1 & 8 & 1 & - & 1 & 12 & $2,2 \%$ \\
\hline Business, Management and Accounting & - & - & 7 & 1 & 3 & - & 11 & $2,1 \%$ \\
\hline Chemical Engineering & - & - & 3 & 1 & - & 1 & 5 & $0,9 \%$ \\
\hline Chemistry & 2 & - & 4 & 2 & - & 1 & 9 & $1,7 \%$ \\
\hline Computer Science & - & - & - & - & - & - & 0 & $0,0 \%$ \\
\hline Decision Sciences & - & - & - & 1 & - & - & 1 & $0,2 \%$ \\
\hline Dentistry & - & 2 & 4 & 2 & - & - & 8 & $1,5 \%$ \\
\hline Earth and Planetary Sciences & - & - & 7 & 4 & 8 & 3 & 22 & $4,1 \%$ \\
\hline Economics, Econometrics and Finance & - & 1 & 8 & 4 & 6 & - & 19 & $3,5 \%$ \\
\hline Energy & - & - & - & - & - & 1 & 1 & $0,2 \%$ \\
\hline Engineering & - & 2 & 6 & 5 & 8 & 1 & 22 & $4,1 \%$ \\
\hline Environmental Science & - & 1 & 6 & 1 & 5 & - & 13 & $2,4 \%$ \\
\hline Health Professions & - & 1 & 3 & - & - & - & 4 & $0,7 \%$ \\
\hline Immunology and Microbiology & - & 1 & 4 & 1 & 2 & - & 8 & $1,5 \%$ \\
\hline Materials Science & - & 1 & 4 & - & 1 & - & 6 & $1,1 \%$ \\
\hline Mathematics & - & - & - & 1 & 3 & - & 4 & $0,7 \%$ \\
\hline Medicine & 10 & 46 & 62 & 11 & 12 & - & 141 & $26,3 \%$ \\
\hline Multidisciplinary & 1 & - & 1 & - & - & - & 2 & $0,4 \%$ \\
\hline Neuroscience & - & - & 1 & - & 1 & - & 2 & $0,4 \%$ \\
\hline Nursing & - & 1 & 4 & 3 & - & - & 8 & $1,5 \%$ \\
\hline $\begin{array}{l}\text { Pharmacology, Toxicology and } \\
\text { Pharmaceutics }\end{array}$ & - & 3 & 3 & 1 & - & - & 7 & $1,3 \%$ \\
\hline Physics and Astronomy & - & 1 & 2 & - & 1 & - & 4 & $0,7 \%$ \\
\hline Psychology & 1 & - & 2 & 6 & 8 & - & 17 & $3,2 \%$ \\
\hline Social Sciences & - & 3 & 13 & 23 & 22 & - & 61 & $11,4 \%$ \\
\hline Veterinary & 1 & 2 & 3 & 1 & 1 & - & 8 & $1,5 \%$ \\
\hline Total & 22 & 77 & 203 & 88 & 132 & 14 & 536 & $100,0 \%$ \\
\hline$\%$ & $4,1 \%$ & $14,4 \%$ & $37,9 \%$ & $16,4 \%$ & $24,6 \%$ & $2,6 \%$ & $100,0 \%$ & \\
\hline
\end{tabular}

Fonte: Dados da pesquisa. 
A alternativa de periodicidade mais adotada pelas revistas é a trimestral, apresentando, no total, 37,9\% (203). Em seguida, está o semestral, com 24,6\% (132) de periódicos, e a quadrimestral com 16,4\% (88).

A periodicidade trimestral é mais adotada pelas áreas da Medicine, com 11,6\% (62) dos títulos e pela Agricultural and Biological Sciences, com $8,4 \%$ (45) de títulos. Poucas revistas adotam a periodicidade mensal em seus títulos.

A área que mais adota a periodicidade quadrimestral é a Social Sciences, que apresenta 4,3\% (23) das revistas. A periodicidade semestral é aceita na área de Agricultural and Biological Sciences, por 5,2\% (28) dos títulos; na área Arts and Humanities, por 4,3\% (23) dos títulos e na Social Sciences, por 4,1\% (22) dos títulos.

A atividade editorial, nos periódicos da amostra, representa a produção de 2.080 fascículos por ano. Considerando-se uma média de 12 artigos em cada número, temos 24.960 artigos publicados por ano. Esta atividade envolve um número significativo de profissionais para atender às etapas necessárias de elaboração de cada número, que incorporam, cada vez mais, recursos digitais, além das tradicionais tarefas de diagramação dos elementos dos fascículos e demais tipos de documento presentes em cada número.

A complexidade das atividades editoriais, a impossibilidade de identificar empresas editoriais que tenham vários títulos, como é o caso em outros países, gera questões para discussão. Segundo os dados, o complexo editorial científico latino-americano é formado por títulos individuais, com editoras muito pequenas e localizadas dentro de universidades e associações. O detalhamento da inserção desses títulos em cada tipo de instituição e das equipes editoriais necessita de novos estudos.

Para o seguimento da análise, será identificado o uso dos recursos digitais: tipos de formato dos arquivos, identificador persistente e registro do Creative Commons. Essas características são exclusivas dos periódicos digitais, adicionando complexidade à gestão e interferem na visualização, preservação e recuperação dos artigos.

A Tabela 9 mostra a distribuição dos arquivos em HTML, PDF, em ambos simultaneamente, indexados em cada plataforma utilizada pelos periódicos e aponta o uso de Identificador permanente. 
Tabela 9 - Formato de arquivo e Identificador persistente organizados por plataforma

Fonte: Dados da pesquisa.

\begin{tabular}{l|c|c|c|c|c|c|c|c|c}
\hline & \multicolumn{4}{|c|}{ Formato de arquivo } & \multicolumn{5}{c}{ Identificador persistente } \\
\hline Plataforma & HTML & PDF & Ambos & Total & DOI & Handle & Outro & N & Total \\
\hline OJS & - & 32 & 15 & 47 & 11 & - & - & 36 & 47 \\
\hline Própria & 15 & 76 & 18 & 109 & 2 & 1 & 1 & 105 & 109 \\
\hline Outra & - & 2 & 2 & 4 & - & - & - & 4 & 4 \\
\hline OJS e Própria & - & 5 & 1 & 6 & 1 & - & - & 5 & 6 \\
\hline Scielo & 2 & 4 & 194 & 200 & 74 & - & - & 126 & 200 \\
\hline OJS e Scielo & - & 1 & 26 & 27 & 16 & - & - & 11 & 27 \\
\hline $\begin{array}{l}\text { Scielo e } \\
\text { Própria }\end{array}$ & 1 & 7 & 130 & 138 & 94 & 1 & - & 43 & 138 \\
\hline $\begin{array}{l}\text { Scielo, OJS e } \\
\text { Própria }\end{array}$ & 1 & - & 4 & 5 & - & - & - & 5 & 5 \\
\hline Total & 19 & 127 & 390 & 536 & 198 & 2 & 1 & 335 & 536 \\
\hline \multicolumn{1}{c}{$\%$} & $3,5 \%$ & $23,7 \%$ & $72,8 \%$ & $100,0 \%$ & $36,9 \%$ & $0,4 \%$ & $0,2 \%$ & $62,5 \%$ & $100,0 \%$ \\
\hline
\end{tabular}

Nota-se que o formato que utiliza simultaneamente as opções HTML e PDF predomina nas plataformas com 72,8\% (390). Logo em seguida, está o formato PDF, que sozinho possui $23,7 \%$ (127) dos títulos, enquanto que só o formato HTML apresenta apenas 3,5\% (19). Verifica-se que a SciELO é responsável pela maioria de títulos que utilizam os formatos de arquivo HTML e PDF simultaneamente, com 37,3\% (200) do total na região.

Em relação ao "Identificador Persistente", verifica-se que 36,9\% (198) das revistas utilizam o Digital Object identifier (DOI) e 62,5\% (335) das revistas não utilizam ou não foi possível identificar algum tipo de identificador persistente. Somente $0,4 \%$ (2) das revistas utilizam o Handle System.

Para analisar o uso de versão impressa e do Creative Commons, foi necessário usar estratégias distintas. Para o item impresso, foram coletadas as informações do Ulrich, pois a página do periódico não informa a existência de versão impressa. Segundo as informações obtidas, a maioria dos periódicos é impressa, com 94,9\% (509) de títulos do total, e apenas 5\% (27) das revistas são exclusivamente digital ou não foi possível localizar a informação.

Cabe destacar a possibilidade dos dados do Ulrich estarem desatualizados em relação a existência de versão impressa, em vários casos as informações que estavam indexadas nessa lista não corresponderam com as que estavam no corpo da revista analisada. Nesse caso, optou-se por considerar a informação da revista, o que levanta outra questão: qual o número real de títulos que ainda adota a alternativa impressa em paralelo à alternativa digital? $E$ como fazer o acompanhamento desse fenômeno com dados atualizados? A diminuição de uso da versão impressa de periódicos já está sendo anunciada desde os final dos anos 90, mas não há informação sobre a velocidade do fenômeno. 
Tabela 10 - Versão impressa e Creative Commons

\begin{tabular}{l|c|c|c|c|c|c}
\hline & \multicolumn{3}{|c|}{ Impresso } & \multicolumn{3}{c}{ Creative Commons } \\
\hline \multicolumn{1}{c|}{ País } & SIM & NÃO & Total & SIM & NÃO & Total \\
\hline Argentina & 38 & 3 & 41 & 4 & 37 & 41 \\
\hline Brasil & 238 & 3 & 241 & 203 & 38 & 241 \\
\hline Chile & 67 & 6 & 73 & 9 & 64 & 73 \\
\hline Colômbia & 32 & 9 & 41 & 7 & 34 & 41 \\
\hline Costa Rica & 2 & - & 2 & - & 2 & 2 \\
\hline Cuba & 20 & 1 & 21 & 18 & 3 & 21 \\
\hline Equador & 2 & - & 2 & - & 2 & 2 \\
\hline México & 73 & - & 73 & 1 & 72 & 73 \\
\hline Peru & 1 & 1 & 2 & - & 2 & 2 \\
\hline Uruguai & 1 & - & 1 & - & 1 & 1 \\
\hline Venezuela & 35 & 4 & 39 & 1 & 38 & 39 \\
\hline Total & 509 & 27 & 536 & 243 & 293 & 536 \\
\hline \multicolumn{1}{c}{$\%$} & $95,0 \%$ & $5,0 \%$ & $100,0 \%$ & $45,3 \%$ & $54,7 \%$ & $100,0 \%$ \\
\hline
\end{tabular}

Fonte: Dados da pesquisa.

Em relação ao Creative Commons, 45,3\% (243) dos periódicos possuem registro e $54,7 \%$ (293) não mencionam o selo na página ou não foi possível localizar a informação. O alto índice de ausência de registro indica desconhecimento da importância ou descaso com o registro ou outras priorizações, em todo caso, mostra a quantidade de detalhes necessários para o registro completo de um periódico.

O Creative Commons é um projeto global, mais de 40 países já possuem a licença (CREATIVE COMMONS, 2012). O objetivo da licença é permitir que os autores exerçam livremente seus direitos, permitindo que músicos, escritores, fotógrafos, jornalistas, entre outros, liberem alguns usos dos seus trabalhos por parte da sociedade (LIMA; SANTINI, 2008; ABADAL et al., 2010).

O uso do Creative Commons se torna importante na medida em que, além de registrar a autoria, impede que materiais sob seu selo sejam comercializados ou sejam usados indevidamente, sendo um recurso para a expressão inequívoca da vontade do autor. As questões relacionadas à normalização se sofisticam cada vez mais, exigindo dos autores acompanhamento minuncioso dos registros dos periódicos, além da gestão dos conteúdos.

\section{Conclusão}

Os periódicos científicos são o principal meio de divulgação dos resultados da Ciência. O avanço tecnológico, migração do formato impresso para o digital, a expansão do Acesso Aberto e o rompimento das barreiras geográficas e de tempo em escala mundial mudam o cenário frequentemente. A barreira de acesso hoje é política e econômica.

A identificação de $98 \%$ dos títulos em Acesso Aberto superou, em muito, a expectativa inicial sobre o alcance da já conhecida opção dos países latino-americanos. A alternativa metodológica adotada no estudo, apesar das limitações, de considerar apenas as duas principais bases indexadoras permitiu que os títulos fossem analisados de forma equivalente entre as áreas e mostrou a importância de dados concretos 
para estudos que possam servir de base para políticas em tema estratégico, como o acesso à informação científica.

Verificou-se que as universidades e associações são as entidades editoriais responsáveis pelo maior índice de títulos em todos os países. As universidades são responsáveis por $45 \%$ dos títulos e as associações por 38\%. Os periódicos estão distribuídos em 11 países, 241 estão no Brasil, seguido do Chile e do México, com 73 periódicos cada. As áreas que mais se destacam em quantidade de periódicos são a Medicine, com 23,9\% do total, a Agricultural and Biological Sciences, com 16,3\% e a Social Sciences, com 15,9\% títulos.

A maioria dos títulos surgiu entre 1981 e 1990 (16\%) ou entre 1991 e 2000 (23\%), o que indica que existiram primeiramente em formato impresso e migraram para o digital. A plataforma SciELO é utilizada por $69 \%$ (370) dos títulos e as periodicidades mais frequentes são trimestral $(38,8 \%)$ e semestral $(23,7 \%)$, gerando estimados 2.080 fascículos por ano.

Os resultados deste trabalho mostram o predomínio absoluto de periódicos em Acesso Aberto na América Latina, tendo como sustentação entidades editoras vinculadas à universidades e associações, registrando de forma inequívoca a viabilidade do modelo Acesso Aberto via dourada, até o momento, nestes países, viável pelo financiamento público e articulação dos envolvidos.

\section{Agradecimentos}

Este estudo foi possível em função da bolsa de Iniciação Científica do CNPq e à colaboração das mestrandas Patrícia Neubert e Luiza Helena Goulart. Agradecemos aos comentários do Prof. Ernest Abadal, em versão preliminar do documento.

\section{Referências}

ABADAL, E. et al. Open access in Spain. In: ANGLADA, L; ABADAL, E. (Eds.). Open access in Southern European countries. Madrid: FECYT, 2010. p. 101-115.

ABADAL, E. Acceso abierto a la ciencia. Barcelona: Editorial UOC, 2012. (Colección El profesional de la información). Disponível em: <http://eprints.rclis.org/bitstream/10760/16863/1/2012-acceso-abiertoepi-uoc-vfinal-autor.pdf $>$. Acesso em: 19 abr. 2012.

ALPERIN, J. P.; FISCHMAN, G. E.; WILLINSKY, J. Open access and scholarly publishing in Latin America: ten flavours and a few reflections. Liinc em Revista, v. 4, n. 2, p. 172-185, set. 2008. Disponível em: <http://openarchive.stanford.edu/sites/default/files/269-950-2-PB.pdf >. Acesso em: 17 mar. 2012.

ARELLANO, F. F. M. (Coord.). Acceso abierto a la información en las bibliotecas académicas de América Latina y el Caribe. México: UNAM, 2011. 352 p. Disponível em: 
<http://132.248.242.3/ publica/archivos/libros/acceso_abierto_informaci on.pdf>. Acesso em: 05 mar. 2012.

BADAT, $\mathrm{S}$. The role of higher education in society: valuing higher education. Africa do Sul: HERS-SA Academy, 2009. p. 13-19. Disponível em: <http://eprints.ru.ac.za/1502/1/badat_hers.pdf>. Acesso em: 27 mar. 2012.

BAILEY Jr., C. What is open access? In: JACOBS, N. (Ed.). Open access: key strategic, technical and economic aspects. Oxford: Chandos Publishing, 2006. Disponível em: <http: // www.digitalscholarship.com/cwb/WhatIsOA.pdf>. Acesso em: 25 mar. 2012.

BARBETTA, P. A. Estatística aplicada às ciências sociais. 5. ed. Florianópolis: Editora da UFSC, 2004.

BJORK, B. et al. Open access to the cientific journal literature: situation 2009. PLos ONE, v. 5, n. 6, 2010. Disponível em: <http://www.plosone.org/article/info:doi/10.1371/journal.pone.0011273

$>$. Acesso em: 1 mar. 2012.

BROWN, D. Repositories and journals: are they in conflit? A literature review of relevant literature. Aslib Proceedings: New Information Perspectives, v. 62, n. 2, 2010. Disponível em: <http://www.emeraldinsight.com/journals. htm?articleid $=1847083 \&$ show $=$ html>. Acesso em: 10 abr. 2012.

BURKE, P. Uma história social do conhecimento: de Gutenberg a Diderot. Rio de Janeiro: Jorge Zahar, 2003.

CANESSA, E.; ZENNARO, M. Science dissemination using open access: a compendium of selected literature on open access. Trieste, Italy: ICTP The Abdus Salam International Centre for Theoretical Physics, jul. 2008. Disponível em : <http://sdu.ictp.it/openaccess/SciDissOpenAccess.pdf>. Acesso em: 21 mar. 2012.

CETTO, A. M.; ALONSO GAMBOA, J. O. (Eds.) Qualidade e impacto da Revista Ibero-Americana [Online]. México: UNAM, 2011. Disponível em: <http://www.latindex.unam.mx/librociri/>. Acesso em: 18 mar. 2012.

CREATIVE COMMONS. Disponível em: <http://creativecommons.org/>. Acesso em: 18 mar. 2012.

DELGADO, J.E. Role of open access in the emergence and consolidation of refereed journals in Latin America and the Caribbean. Revista Educación Superior y Sociedad (UNESCO-IESALC),v. 16, n.2, 2011.Disponível em: http://ess.iesalc.unesco.org.ve/index.php/ess/article/viewArticle/407.

Acesso em: 12 jun 2012.

FERREIRA, S. M. Estruturas contemporâneas de comunicação científica e a organização institucional. Encontros Bibli: Revista Eletrônica de Biblioteconomia e Ciência da Informação, Florianópolis, v. 13, n. 26, 2008. Disponível em: <http://www.periodicos.ufsc.br/index.php/eb/article/view/8346/7683>. Acesso em: 5 mar. 2012.

FREIRE, G. H. Ciência da Informação: temática, histórias e fundamentos. Perspectivas em ciência da informação, Belo Horizonte, v. 11, n. 1, p. 619, jan./abr. 2006. Disponível em: 
<http://www.scielo.br/pdf/pci/v11n1/v11n1a02.pdf >. Acesso em: 25 mar. 2012.

GAMBOA, J. O.; ISLAS, L. A. Revistas electrónicas en America latina: um panorama general. Revista Digital Universitaria, v. 6, n. 1, 2005. Disponível em: <http://www.revista.unam.mx/>. Acesso em: 2 mar. 2012

GARRIDO, I. dos S.; RODRIGUES, R. Portais de periódicos científicos online: organização institucional das publicações. Perspectivas em Ciência da Informação, v. 15, p. 56-72, 2010.

GIL, A. C. Como elaborar projetos de pesquisa. 4. ed. São Paulo: Atlas, 2002.

GUÉDON, J. Oldenburg's long shadow: librarians, research scientists, publishers, and the control of scientific publishing. Association of Research Libraries. $2001 . \quad$ Disponível em: <http://www.arl.org/resources/pubs/mmproceedings/138guedon.shtml>. Acesso em: 2 abr. 2012.

KURAMOTO, H. Informação científica: proposta de um novo modelo para o Brasil. Ciência da informação, Brasília, v. 35, n. 2, p. 91-102, maio/ago. $2006 . \quad$ Disponível em: <http://www.scielo.br/pdf/ci/v35n2/a10v35n2.pdf>. Acesso em 17 mar. 2012.

LIMA, C. R. M.; SANTINI, R. M. Produção colaborativa de softwares livres. Informação \& Sociedade: estudos, João Pessoa, v. 18, n. 2, p. 114, maio/ago. $2008 . \quad$ Disponível em: <http://ibict.phlnet.com.br/anexos/mioloproducaonovo.pdf>. Acesso em: 29 mar. 2012.

MARCONDES, Carlos Henrique. Et al. Evaluation of emerging ejournals in science and technology: a proposed methodology based on analysis of links to ejournal s site. In: ICCC INTERNATIONAL CONFERENCE ON ELECTRONIC PUBLISHING, 8., 2004. Department of Information Science and Documentaion, University of Brasilia, 2004. p. 171-180.

MEADOWS, A. J. A comunicação científica. Brasília: Brinquet de Lemos, 1999.

MOREIRA, S. V. . Análise documental como método e como técnica. In: Jorge Duarte; Antonio Barros. (Org.). Métodos e Técnicas de Pesquisa em Comunicação. 1ed.São Paulo: Atlas, 2005. p. 267-279.

MUELLER, S. P. M. A comunicação científica e o movimento de acesso livre ao conhecimento. Ciência da Informação, Brasília, v. 35, n. 2, p. 27-38, maio/ago. 2006. Disponível em: <http://revista.ibict.br/ciinf/index.php/ciinf/issue/view/35/showToc>.

Acesso em: 27 mar. 2012.

MUELLER, S. P. M. Produção e financiamento de periódicos científicos de acesso aberto: um estudo da base SciELO. In: POBLACIÓN, D. A.; WITTER, G. P.; RAMOS, L. M. S. V. C. (Orgs.). Dos processos tradicionais às perspectivas alternativas de comunicação. São Paulo: Ateliê Editorial, 2011.

PATALANO, M. Las publicaciones del campo científico: las revistas académicas de América. Anales de Documentacion, n. 8, p. 217-235, 
2005.

<http://digitum.um.es/xmlui/bitstream/10201/3960/3/1501.pdf>. Acesso em: 2 abr. 2012.

RODRIGUES, R. S.; FACHIN, G. R. B. Portal de periódicos científicos: um trabalho multidisciplinar. Transinformação, v. 22, p. 33-45, 2010.

SAMPIERI, R. H.; COLLADO, C. F.; LUCIO, P. B. Metodologia da pesquisa. 3. ed. São Paulo: McGraw-Hill, 2006.

SANTOS JUNIOR, E. R. dos. Repositórios institucionais de acesso livre no Brasil: estudo delfos. 2010. 177f. Dissertação (Mestrado em Ciência da Informação) - Universidade de Brasília, Brasília, 2010. Disponível em: <http://repositorio.bce.unb.br/bitstream/10482/5343/6/2010_ErnaniRufin odosSantos] unior.pdf>. Acesso em: 3 mar. 2012.

SAYÃO, L. F. Repositórios digitais confiáveis para a preservação de periódicos eletrônicos científicos. Ponto de Acesso, Salvador, v. 4, n. 3, p. 68-94, 2010. Disponível em: <http://www.portalseer.ufba.br/index.php/revistaici/article/view/4709/35 65>. Acesso em: 12 mar. 2012.

SCIELO. Scientific Eletronic Library Online. Disponível em: <http://www.scielo.org/php/index.php>. Acesso em: 21 mar. 2012.

SCIVERSE SCOPUS. Disponível em: <http://www.info.sciverse.com/scopus>. Acesso em: 27 mar. 2012

SILVA, J. F. M. da; SANTOS, M. dos; PRAZERES, A. P. P. dos. Incubadora de revistas científicas. In: POBLACIÓN, D. A.; WITTER, G. P.; RAMOS, L. M. S. V. C. (Orgs.). Dos processos tradicionais às perspectivas alternativas de comunicação. São Paulo: Ateliê Editorial, 2011.

STUMPF, I. R. C. Passado e futuro das revistas científicas. Ciência da Informação, $\quad$. 25, n. 3, 1996. Disponível em: <http://revista.ibict.br/ciinf/index.php/ciinf/article/view/463/422>.

Acesso em: 25 mar. 2012.

SWAN, A. Why open access for Brazil? Liinc em Revista, v. 4, n. 2, 2008. Disponível em: <http://revista.ibict.br/liinc/index.php/liinc/article/view/279>. Acesso em: 9 mar. 2012.

TERRA-FIGARI, L. I. Diseminación del conocimiento académico en América Latina. Montevideo. In: ANTROPOLOGÍA Social Y Cultural En Uruguay 2007. Uruguay: UNESCO, 2008.

THOMSON REUTER. Disponível em: <http://thomsonreuters.com/>. Acesso em: 27 mar. 2012.

TRONCOSO, J. D. Papel del Acceso Abierto en el surgimiento y consolidación de las revistas arbitradas en América Latina y el Caribe. Educación Superior y Sociedad, Caracas, v. 16, n. 2, 2011. Disponível em:

<http://ess.iesalc.unesco.org.ve/index.php/ess/article/viewArticle/408>.

Acesso em: 10 mar. 2012. 
VILLARROYA, A. et al. Modelos de negocio de las editoriales de revistas científicas: implicaciones para el acceso abierto. El profesional de la información, v. 21, p. 129-135, 2012.

WHITLEY, R. The social and intellectual organization of the sciences. Oxford: Oxford University Press, 1984.

RODRÍGUEZ-YUNTA, L. Las revistas iberoamericanas en Web of Science y Scopus: visibilidad internacional e indicadores de calidad, 2010. In:SEMINARIO HISPANO-MEXICANO DE INVESTIGACIÓN EN BIBLIOTECOLOGÍA Y DOCUMENTACIÓN, Ciudad de México, 7., 7-9 de abril de 2010. Anais. México: UNAM, 2011. p. 347-363. Disponível em: <http://eprints.rclis.org/bitstream/10760/14490/1/LuisRY7Encuentro.pdf $>$. Acesso em: 25 mar. 2012.

ZIMAN, J. Conhecimento público. Belo Horizonte: Itatiaia; São Paulo: Ed. Univ. S. Paulo, 164p, 1979.

ZIMAN, J. A força do conhecimento: a dimensão científica da sociedade. Sao Paulo: Itatiaia : USP, 1981. 